\title{
Terminology and classification of acute mountain sickness
}

\author{
J G DICKINSON
}

There are several unsolved questions about acute mountain sickness. Climbers and trekkers want to know how to recognise cases, how to assess their severity, and how to act to avoid deaths. They also need clear guidance about prevention, a subject that has stimulated much correspondence after recent articles. ${ }^{12}$ Medical scientists who are called on to advise on these matters have many fascinating puzzles about the nature of acclimatisation and the disordered physiology that leads to the various manifestations of acute mountain sickness.

Solution of these problems could be helped only by agreement on a logical terminology and classification of acute mountain sickness. In my opinion many of the terms currently used (table) seem to prejudge unsolved pathophysiological questions, render the training of unqualified personnel difficult, and are,

Terms used to describe acute mountain sickness

\begin{tabular}{ll}
\hline \multicolumn{1}{c}{ Common terms } & \multicolumn{1}{c}{ Approximate synonyms } \\
\hline Acute mountain sickness & $\begin{array}{l}\text { Acute altitude sickness } \\
\text { Soroche, puna } \\
\text { Cardiac puna }\end{array}$ \\
High altitude pulmonary oedema & $\begin{array}{l}\text { Acute pulmonary oedema of altitude } \\
\text { Pulmonary oedema of high altitude } \\
\text { Nervous puna } \\
\text { Brain oedema } \\
\text { Cerebral form of mountain sickness } \\
\text { Acromaladaptation }\end{array}$ \\
\hline
\end{tabular}

in any case, used in different ways by different authorities. Some, for instance, reserve the term "acute mountain sickness" for the relatively mild and common symptoms experienced by many who ascend rapidly, whereas most authors would use it to cover the whole range of acute altitude effects, leaving themselves without a specific term for the milder state. Variants of the terms "high altitude pulmonary oedema" and "high altitude cerebral oedema" occur often, implying that we have only to uncover the pathophysiology of oedema to say all that needs to be said about the condition. Yet necropsy studies show thrombosis in both lung ${ }^{3-6}$ and brain, ${ }^{5}$ infection and atelectasis in the lung, ${ }^{356}$ and haemorrhage in the brain. ${ }^{6-8}$ Admittedly, some of these effects may be secondary, but this is not proved, and there is good evidence that thrombosis at least is an important and possibly primary event. Patients may be deeply unconscious without clinical evidence of cerebral oedema. ${ }^{6}$ Neuronal transmitter depletion ${ }^{9}$ and membrane depolarisation ${ }^{10}$ may also be important causes of cerebral effects of altitude.

Shanta Bhawan Hospital, Katmandu, Nepal

J G DICKINSON, DM, FRCP, physician

\section{Relationship uncertain}

The relationship between the common, milder forms of acute mountain sickness and the rarer, more severe forms is still uncertain. Some patients certainly seem to progress from mild to severe states, so that the former may well be a useful warning of the risk of the latter. On the other hand, some patients seem to develop life-threatening disease with little or no useful warning. A recent patient of mine, for example, retired to her tent without any complaint but could not be woken in the morning. Are the pathophysiological processes that lead to severe cases of acute mountain sickness simply an extension of those that lead to lesser symptoms, or are they different in type ? One piece of evidence suggesting that they may be different comes from a recent study of acetazolamide prophylaxis in which the drug generally prevented symptoms but did not prevent one climber from developing severe acute mountain sickness. ${ }^{1}$ The fact that the severe forms are less common (only $4.3 \%$ of trekkers in the series of Hackett et $a^{l^{11}}$ ) makes the effect of prophylaxis more difficult to assess by controlled study. In the present state of understanding, terminology should leave the way open for both the recognition of possible progression of the disease and also for the possibility of distinct processes. This will not only help conceptually, but will also avoid the possibly false conclusion that acetazolamide, because it reduces hypoxaemia ${ }^{2}$ and especially sleep hypoxaemia ${ }^{12}{ }^{13}$ and reduces symptoms, will necessarily prevent fatalities.

\section{Proposed agreed descriptions}

Perhaps most important of all, the agreed terminology and disease descriptions should guide non-qualified personnel in their management of companions ascending to high altitude. They need to know who must be sent down urgently, who should remain at their current altitude, and who may be allowed to continue ascent.

I believe the most appropriate classification and terminology to be as follows:

Acute mountain sickness

Benign acute mountain sickness

Malignant acute mountain sickness

(a) Cerebral acute mountain sickness

(b) Pulmonary acute mountain sickness

(c) Mixed forms (cerebral + pulmonary)

\section{ACUTE MOUNTAIN SICKNESS}

\section{Benign}

Benign may be recognised by a combination of several of the following symptoms: headache, nausea, anorexia, vomiting, weakness, insomnia, light-headedness, and, possibly, a feeling of discomfort in the chest. There are no abnormal physical signs. 


\section{Malignant acute mountain sickness}

(a) Cerebral acute mountain sickness may be diagnosed by the presence of one or more neurological features of which the most common are ataxia, irritability and abnormal behaviour, drowsiness, hallucinations, coma, abnormalities of limb tone, and urinary incontinence. Papilloedema may be present. Other abnormalities such as cranial palsies and tremor sometimes occur.

(b) Pulmonary acute mountain sickness is indicated by dyspnoea that is present at rest, cough, and white frothy sputum. Basal crepitations, tachypnoea, and cyanosis may also be found.

(c) Mixed forms-Features of $(a)$ and $(b)$ combined.

Most critical features may be recognised by non-medically qualified people, who should therefore be able to recognise all three forms of malignant acute mountain sickness and respond by evacuating the victim from high altitude as soon as possible. If a person has only the features of benign acute mountain sickness, without any of those described under malignant acute mountain sickness, he or she may be kept under observation at the current altitude and observed for the development of malignant features.

The conditions of high altitude retinal haemorrhage and high altitude subcutaneous oedema should be regarded as separate from acute mountain sickness, but related to it. They may occur in individuals who are otherwise well, or they may occur in association with either benign or malignant acute mountain sickness. They are, therefore, not helpful in decision-making.

Those who have an interest in the history of the subject will note the similarity of this proposed classification to that given by Ravenhill in $1913^{14}$ on the basis of his experience in the Chilean Andes. He used the local term "puna," and described "normal puna," "cardiac puna," and "nervous puna." Except that we now recognise that the dyspnoea is pulmonary rather than cardiac in origin, this classification would serve admirably today.

The use of the terms "benign" and "malignant" in my proposed terminology may attract criticism as being unduly dramatic. Nevertheless, this is in fact one of the main advantages of using them as there seems to be insufficient public awareness of the fact that acute mountain sickness may be truly "malignant" in the sense of leading to death if not correctly managed.
"Benign" implies that the condition is not life-threatening, but in no way denies that it might later become so. Progression from benign to malignant is well recognised in other medical conditions, and the terms are fairly well known to the public.

This article asks the question whether it is possible to agree on a terminology that is accurate up to the point of our present knowledge but not beyond, which forms a useful basis for communication and further study, and which allows helpful instruction for those who go to high altitude. I believe the proposed terminology meets these criteria.

\section{References}

${ }^{1}$ Greene MK, Kerr AM, McIntosh IB, Prescott RJ. Acetazolamide in prevention of acute mountain sickness: a double-blind controlled crossover study. Br Med F 1981 ;282:811-3.

2 Birmingham Medical Research Expeditionary Society. Acetazolamide in control of acute mountain sickness. Lancet 1981 ; i:180-3.

${ }^{3}$ Hultgren H, Spickard W, Lopez C. Further studies of high altitude pulmonary oedema. Br Heart $\mathcal{f} 1962$;24:95-101.

4 Arias-Stella J, Kruger H. Pathology of high altitude pulmonary oedema. Arch Pathol 1963;ii:147-57.

5 Nayak NC, Roy S, Narayanan TK. Pathologic features of altitude sickness. Am $\mathcal{F}$ Pathol 1974 ;45:381-91.

${ }^{6}$ Dickinson JG. Acute mountain sickness. Oxford: University of Oxford, 1981. (DM Thesis.)

'Wilson R. Acute high-altitude illness in mountaineers and problems of rescue. Ann Intern Med 1973;78:421-8.

${ }^{8}$ Wilson R, Mills WJ, Rogers DR, Propst MT. Death on Denali. West $\mathcal{F}$ Med 1978;128:471-6.

${ }^{9}$ Siesjö BK. Brain energy metabolism. New York: John Wiley and Sons, 1978:398-526.

${ }^{10}$ Lipton P, Whittingham TS. Cerebral neuronal transmission. Seminars in Respiratory Medicine 1981 ;3:68-9.

${ }^{11}$ Hackett PH, Rennie D, Levine HD. The incidence, prophylaxis and importance of acute mountain sickness. Lancet 1976;ii:1149-55.

12 Weil JV, Kryger MH, Scoggin CH. Sleep and breathing at high altitude. In: Guilleminault C, Dement WC, eds. Sleep apnoea syndromes. New York: Alan R Liss Inc, 1978.

13 Sutton JR, Houston CS, Mansell AL, et al. Effect of acetazolamide on hypoxaemia during sleep at high altitude. $N$ Engl $\mathcal{f}$ Med 1979;301: 1329-31.

14 Ravenhill TH. Some experiences of mountain sickness in the Andes. $\mathcal{f}$ Trop Med Hyg 1913;20:313-20.

(Accepted 18 March 1982)

\section{MATERIA NON MEDICA}

\section{Fire ceremony}

In Allendale they saw out 1981 in traditional style. New Year's Eve was cold, crisp, and bright; there was no wind and little cloud. Under the star-studded sky the snow was clean and white and still. The roads were clear, running between the banked work of the snowploughs, so the people of the valley converged on the town whereas many outsiders stayed away from the fire ceremony this year.

We set out early and called on friends of my hosts. While we were being entertained with drinks and home-made delicacies two guisers arrived. One was a pearly king in a top hat, heavily made up and with a curly mustachio. His companion was wearing an Old Mother Riley bonnet, a ginger wig, a long black dress, and an orange petticoat with a fringe. The petticoat was said to be fifty years old. The ladies were intrigued, especially when they found that it was being worn upside down.

At the next call we were refreshed again. There was another guiser, dressed in a lion outfit, and he showed us his barrel which he was going to carry in the procession. It was filled with wood shavings and paraffin and was well charred from previous years. His young lady companion was wearing a flowered straw hat and a long pink dress and white gloves. On a closer inspection-prompted by her irregular bosom-she turned out to be another guiser, a young man who was old enough to take part for the first time. Only men born in Allendale may be guisers, a restriction said to be resented by some feminists.

Meanwhile the crowd was gathering around the $10 \mathrm{ft}$ high bonfire in the Market Square and was singing to the accompaniment of the town band. At ten to twelve the assembled guisers hoisted their barrels on their heads for the torchbearer to light. There were the Pirate, the Housemaid, the Highwayman, the Red Indian, the Nurse, the Black King, and others. The Shepherd was Palestinian, not Northumbrian. The procession formed up with the band and they marched round the town, presumably cleansing it of all the year's ills. They arrived back in the square at midnight and the torchbearer set light to the bonfire while the guisers circled round it. We all wished one another a Happy New Year and the lads kissed the lasses and the church bells joined in the clamour. Then we all sang "Auld Lang Syne" and after that started to move out through the town and into the hills to first-foot friends and neighbours.

The older inhabitants told me that the fire ceremony is older than memories run, but a letter to The Times from University College, London-that citadel of utilitarianism and no nonsense-assures us that it and others like it are of comparatively recent origin. And I had been wondering what the Roman soldiers on the Wall had thought of it!-W L JONES, retired consultant psychiatrist, Nottingham. 